\title{
Pattern of heart failure in a Nigerian teaching hospital
}

This article was published in the following Dove Press journal:

Vascular Health and Risk Management

4 September 2009

Number of times this article has been viewed

\section{Arthur C Onwuchekwa Godspower E Asekomeh \\ Department of Internal Medicine, University of Port Harcourt Teaching Hospital, Port Harcourt, Rivers State, Nigeria}

Correspondence:Arthur C Onwuchekwa Department of Internal Medicine, University of Port Harcourt Teaching Hospital, Port Harcourt, Rivers State, Nigeria

Tel +2348033421872

Email ac_onwuchekwa@yahoo.com
Background: Congestive cardiac failure (CCF) has emerged as a major public health problem worldwide and imposes an escalating burden on the health care system.

Objective: To determine the causes and mortality rate of CCF in the University of Port Harcourt Teaching Hospital (UPTH), south Nigeria, over a five-year period from January 2001 to December 2005.

Methods: A retrospective study of CCF cases were identified from the admission and discharge register of the medical wards of UPTH and the case notes were retrieved from the medical records department and analyzed.

Results: There were 423 patients: 242 males and 181 females. Their ages ranged from 18 to 100 years with a mean of $54.4 \pm 17.3$. The commonest causes of CCF were hypertension $(56.3 \%)$ and cardiomyopathy (12.3\%). Chronic renal failure, rheumatic heart disease, and ischemic heart disease accounted for $7.8 \%, 4.3 \%$, and $0.2 \%$ of CCF, respectively. Peripartum heart disease was rare despite being commonly reported in northern Nigerian females. Eighteen patients died from various complications with a mortality rate of $4.3 \%$.

Conclusion: The burden of CCF in the Niger Delta is mainly attributed to hypertension. Efforts should be geared towards hypertension awareness, detection, treatment, and prevention in the region.

Keywords: pattern, cardiac failure, Nigeria, etiological factors

\section{Introduction}

Diseases of the cardiovascular system vary throughout the world in type and distribution especially between the developed and the developing countries. Whereas in the former, coronary artery disease is the leading cause of heart failure, in the later, it is rare. ${ }^{1}$ In Nigeria, hypertension and rheumatic heart disease are high on the list of causes of heart failure. ${ }^{1,2}$ Climate, genetic, and socioeconomic factors are given as possible reasons for these differences, but they operate between and within developing countries. ${ }^{3}$

In Africa, reports of the causes of heart failure are available in Ghana, ${ }^{2}$ Cameroon, ${ }^{4}$ and South Africa. ${ }^{5}$ In Nigeria, there are recent reports from Ile-Ife in southwest Nigeria, ${ }^{6}$ Kaduna, Zaria, and Katsina in northern Nigeria. ${ }^{3,7,8}$ Data from the Niger Delta basin in the south of Nigeria is scanty. The University of Port Harcourt Teaching Hospital (UPTH) serves as a referral centre for most of this region.

The aim of this study is to determine the frequency, etiologies, and the hospital mortality of congestive cardiac failure (CCF) in this setting. submit your manuscript | www.dovepress.com

Dovepress 


\section{Patients and methods}

The case records of all adult Nigerian natives aged 18 years and above with a clinical diagnosis of CCF and managed in the medical wards between January 2001 and December 2005 (inclusive) were identified from the ward records. These were retrieved from the Records Department of the UPTH. Information on sociodemographic and clinical parameters such as age, sex, occupation, social history, degree of physical activity prior to illness, alcohol and smoking history and treatment outcome were extracted from the case records.

Clinical diagnosis of CCF was based on the modified Framingham criteria. ${ }^{9}$ A patient was considered to have hypertensive heart failure on the basis of self reported history of hypertension and/or the use of blood pressure-lowering medication in addition to the criteria of heart failure as stated above or had documented blood pressure $\geq 140 / 90 \mathrm{mmHg} .{ }^{10}$ Chronic alcohol ingestion was based on self report of intake of $\geq 80 \mathrm{~g}$ of alcohol daily for at least three years. ${ }^{11}$ Dilated cardiomyopathy was defined by the presence of dilated left ventricle (with or without dilatation of the other three cardiac chambers) with global systolic and diastolic dysfunction. ${ }^{12}$ Peripartum cardiomyopathy was diagnosed if echocardiography had revealed features of dilated cardiomyopathy (mentioned above) in the absence of a demonstrable cause or other structural heart disease and if heart disease was identified for the first time within the last trimester of pregnancy or in the first five months postpartum. ${ }^{12}$

Diabetes mellitus was defined as random glucose level of $11.1 \mathrm{mmol} / \mathrm{L}$, or greater, and/or fasting blood sugar of $7.0 \mathrm{mmol} / \mathrm{L}$ or greater, ${ }^{10}$ and/or use of insulin or an oral hypoglycemic agent. Severe anemia was defined as hemoglobin level $<7 \mathrm{gm} / \mathrm{dl}$ ).

Renal impairment was defined as serum creatinine of $>176 \mathrm{mmol} / \mathrm{L}(>2 \mathrm{mg} / \mathrm{dL}) .{ }^{12}$ Thyroid function tests were carried out on those clinically suspected to have thyrotoxic heart failure. Echocardiographic features of rheumatic heart disease were as defined by some workers. ${ }^{13}$ Ischemic heart disease was diagnosed if the patient had either positive history of typical angina or acute myocardial infarction, and/or typical echocardiography (ECG) abnormalities of acute myocardial infarction or myocardial ischemia, plus ventricular regional wall motion abnormality on 2DECG. ${ }^{12}$ 12-lead standard ECGs were as reported by the specialist physician. Chest X-ray report was based on the report of the radiologist.

The cause of mortality was ascertained based on the clinical, radiological, electrocardiographic, echocardiographic, and biochemical reports. All cases in which the cause of mortality was not certain were included as part of missing data.

\section{Inclusion criteria}

The study included adult Nigerians, aged 18 years and above, who were admitted to the medical wards for the first time with a clinical diagnosis of CCF, and who met the Framingham criteria for the diagnosis of heart failure. Any patient who had been admitted previously for heart failure was also included.

\section{Exclusion criteria}

The study excluded patients admitted with suspected heart failure who could not meet the diagnostic clinical criteria for the diagnosis of CCF and those who died within 24 hours of admission before full clinical evaluation was taken.

\section{Statistics}

Data analysis was completed with SPSS software (version 11.1, SPSS Inc, Chicago, IL, USA). Means and standard deviations were computed for quantitative variables and the Student's $t$-test was used to compare means. A $P$ value of $<0.05$ was considered significant.

\section{Results}

\section{Age and sex distribution}

Four hundred and twenty-three patients were admitted into the medical wards with a clinical diagnosis of CCF over the study period. This constituted $9.6 \%$ of a total of 4388 patients admitted over the same period. There were 242 males (57.2\%) and 181 females $(42.8 \%)$, with a male to female (M:F) ratio of 1.34:1. The mean age of the patients was $54.4 \pm 17.3$ years (male: $54 \pm 16.3$ years; female: $54.9 \pm 18.6$ years), with a range of 18-100 years. The age and sex distribution of the patients is as shown in Figure 1.

\section{Etiology}

Two hundred and thirty-eight (56.3\%) patients were admitted and managed for heart failure secondary to hypertension. There were 132 (55.5\%) males and $106(44.5 \%)$ females in this group. Fifty-two patients ( 30 males and 22 females) were managed for CCF secondary to various cardiomyopathies. The predominant types were idiopathic dilated cardiomyopathy $31(7.3 \%)$, diabetes mellitus $9(2.1 \%)$, HIV $6(1.4 \%)$, alcohol 5 (1.2\%), and restrictive idiopathic cardiomyopathy 1 $(0.2 \%)$. There were 18 cases of CCF secondary to rheumatic valvular (mainly mitral) heart disease. These were made up of $13(72.2 \%)$ females and $5(27.8 \%)$ males. The mean 


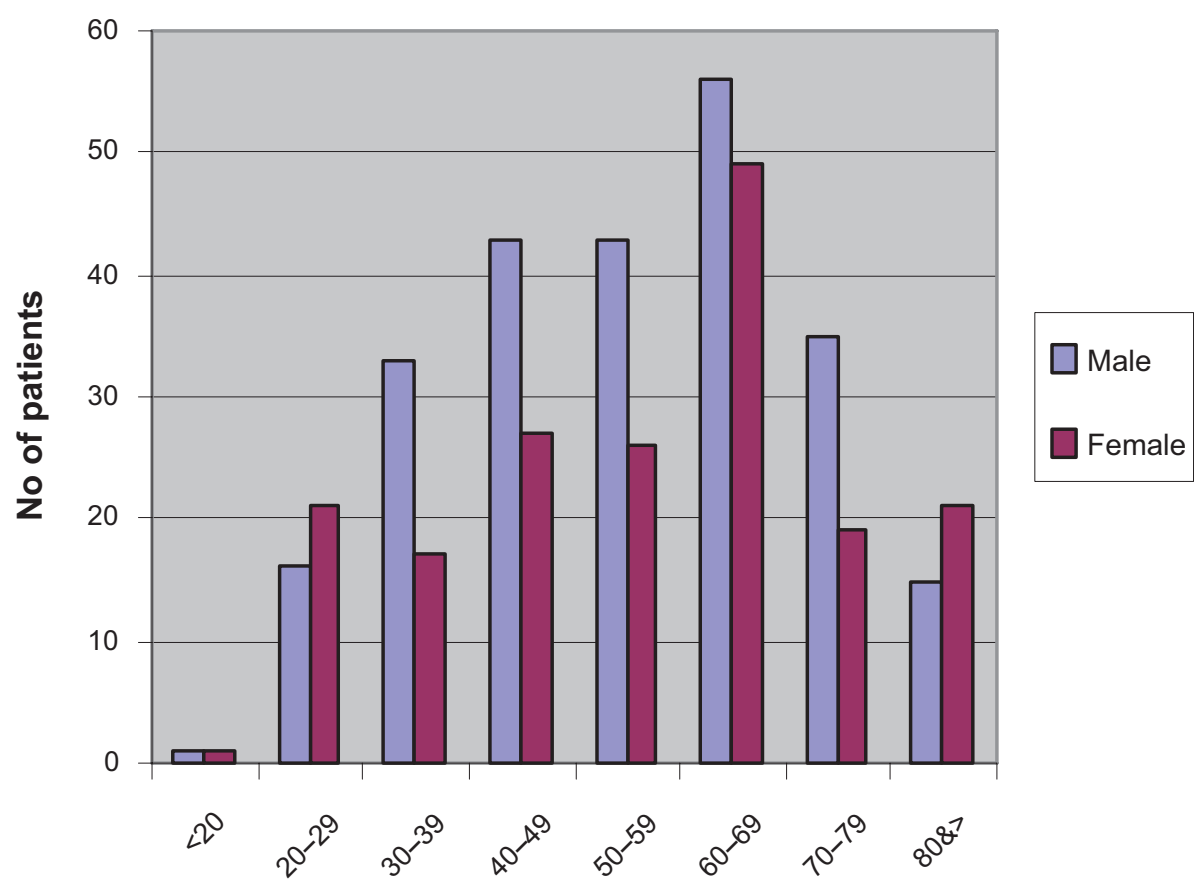

Age range

Figure I Bar chart of age (years)/sex distribution of patients with heart failure.

age for this group was $35.7( \pm 14.2)$ years. A male patient aged 30 years had ventricular septal defect.

Severe anemia $(\mathrm{Hb}<7 \mathrm{gm} / \mathrm{dL})$ accounted for $20(4.8 \%)$ cases of CCF. This consisted of $10(50.0 \%)$ males and $10(50.0 \%)$ females. The common causes of anemia included worm infestations (12), anemia from chronic diseases (6) and hematological malignancies (4).

A total of nine patients had Cor-pulmonale from obstructive airway disease. There were $7(77.8 \%)$ males and $2(22.3 \%)$ females.

Chronic renal failure was the cause of 33 cases of CCF. These were mainly due to chronic hypertensive nephrosclerosis. This consisted of $23(69.8 \%)$ males and $10(30.2 \%)$ females. Four patients had thyrotoxic heart failure with a patient presenting with heart failure due to ischemic heart disease. The causes of CCF in 47 (11.1\%) patients could not be ascertained from the records. Of the total number of patients with clinical features of CCF, 408 had chest X-ray, 312 had resting ECG, while only 146 had echocardiography.

Table 1 shows the frequency of the etiological distribution of the causes of CCF in these patients.

\section{Mortality}

Eighteen patients died: 10 (55.6\%) females and 8 (44.4\%) males. This constituted a mortality rate of $4.3 \%$. Twelve of the deaths were attributed to hypertension with a case fatality rate (CFR) of $5.04 \%$. Cardiomyopathy accounted for six deaths with a CFR of $8.7 \%$, while ischemic heart disease and RHD accounted for one death each, with CFR of $100 \%$ and $5.5 \%$, respectively.

\section{Discussion}

Congestive cardiac failure is an important cardiovascular event that is increasing in incidence and prevalence worldwide. A common and severe condition in Africa, it remains the commonest complication of hypertension and cardiomyopathy. ${ }^{7}$ Hypertension and heart failure constitute a double burden of cardiovascular disease in Nigeria where the age-adjusted prevalence of hypertension is between $20 \%-25 \% .{ }^{14}$ In a recent study from southwest Nigeria, heart failure and hypertension represented $35 \%$ and $32 \%$ of cardiovascular diseases that presented over a five-year period, respectively. ${ }^{15}$ Heart failure was also found to be the third commonest noncommunicable cause of admission (next to diabetes and its complications and cerebrovascular disease) from 1999-2004 in UPTH. ${ }^{16}$

The mean age of patients seen over the study period was 54.4 years with the modal age group being the seventh decade for both male and female patients. In this study, 89 (21\%) patients with CCF were aged less than 40 years 
Table I Distribution of etiology of heart failure in 423 patients

\begin{tabular}{lllll}
\hline Etiology & Male & Female & Total & $\%$ \\
\hline Hypertension & 132 & 106 & 238 & 56.3 \\
$\begin{array}{l}\text { Cardiomyopathies } \\
\quad \text { Dilated }\end{array}$ & 20 & 11 & 31 & 7.3 \\
$\quad$ Diabetes mellitus & 2 & 7 & 9 & 2.1 \\
HIV & 4 & 2 & 6 & 1.4 \\
$\quad$ Alcoholic & 3 & 2 & 5 & 1.2 \\
$\quad$ Restrictive & $\mathrm{I}$ & 0 & $\mathrm{I}$ & 0.2 \\
Chronic renal failure & 23 & 10 & 33 & 7.80 \\
Severe anemia & 10 & 10 & 20 & 4.72 \\
Rheumatic heart diseases & 5 & 13 & 18 & 4.26 \\
Cor pulmonale & 7 & 2 & 9 & 2.13 \\
Congenital valvular heart & $\mathrm{I}$ & 0 & $\mathrm{I}$ & 0.24 \\
disease & & & & \\
Ischemic heart disease & $\mathrm{I}$ & 0 & $\mathrm{I}$ & 0.24 \\
Missing & 32 & 15 & 47 & $\mathrm{II} .1 \mathrm{I}$ \\
Total & 242 & $18 \mathrm{I}$ & 423 & 100 \\
\hline
\end{tabular}

while 334 (79\%) were aged above 40 years. Cardiovascular events are often the commonest illnesses among elderly persons in Nigeria. ${ }^{17}$ This observation is also seen worldwide. In the United States of America, heart failure accounts for $20 \%$ of all admissions among patients older than 65 years. ${ }^{18}$ Advancing age is an independent risk factor for cardiovascular events. ${ }^{19}$

The most frequent cause of heart failure over the study period was hypertension (56.3\%). This is in keeping with reports from other centers in Nigeria. ${ }^{3,7,8}$ Most patients are not aware of being hypertensive and, even when diagnosis has been made, treatment is either not optimal or completely inadequate. ${ }^{20}$ Cardiac complications remain the commonest complication of long-standing hypertension in developing countries. ${ }^{21}$ Some workers in Nigeria, ${ }^{22,23}$ have reported that hypertension often occurs in association with other cardiovascular risk factors like diabetes mellitus, chronic alcohol intake, severe anemia. This clustering pattern is frequent in sub-Saharan Africa and further increases the risk of target organ damage such as CCF.

Cardiomyopathies constituted the second most frequent etiology of heart failure seen in this study, accounting for $10.17 \%$. Cardiomyopathy was the third leading cause of heart failure in a report from Ghana, contributing to $16.8 \%$ of all cases of heart failure in that centre. ${ }^{2}$ Diabetes as a cause of heart failure was seen in some of our patients. Similar observations have been made by others. ${ }^{24}$ Diabetes-related cardiovascular complications, hitherto considered to be rare in Africa, are now on the rise with up to $50 \%$ of diabetic patients having cardiomyopathy in some series. ${ }^{25}$ Valid conclusions cannot be made in these cases because of the absence of stress ECG or coronary angiography.

Although chronic renal failure was often found in a setting of hypertension in this group of patients, renal dysfunction itself is independently associated with the development of heart failure in hypertensive patients. ${ }^{26}$

Anemic heart failure constituted $6.15 \%$ of all the cases seen. Anemia from malnutrition, chronic illnesses, chronic infection, and infestation remain quite prevalent in developing countries. The high prevalence of HIV/AIDS in Nigeria and indeed sub-Saharan Africa has contributed significantly to the increase in the prevalence of heart failure. ${ }^{27}$ The role HIV plays in the development of heart disease is not fully understood. ${ }^{28}$ It may be attributed to generalized illness or co-infection with other viruses. Poor nutrition and wasting may contribute to heart disease while there are anecdotal reports that have suggested that antiretroviral therapy, including protease inhibitors may increase the risk of heart disease. ${ }^{28}$ Other potential mechanisms for heart failure in HIV patients include viral myocarditis, congestive cardiomyopathy, infective endocarditis, and vasculitis secondary to opportunistic infections. ${ }^{29}$

Rheumatic heart disease constituted only $4.26 \%$ of all cases of heart failure amongst the admitted patients. Compared to reports from some parts of northern Nigeria which reported prevalence rates of $14.4 \%{ }^{7}$ and $7.8 \%,{ }^{13}$ respectively, the prevalence of rheumatic heart diseases is low in our study. We speculate that the modest improvement in health care delivery system in this region as well as better housing and better nutrition may have contributed to this observation.

In keeping with findings from other centers in the developing world, with rates of $1.53 \%$ in Cameroon, ${ }^{30}$ and $1.3 \%$ in Kano, northern Nigeria, ${ }^{31}$ our prevalence of ischemic disease of $0.24 \%$ is low. The prevalence of atherosclerosis and coronary artery disease (CAD) and its complications such as myocardial infarction and other degenerative disorders in developing countries remains low, but the situation is rapidly changing. ${ }^{32}$ One of the reasons for the reported low prevalence of CAD in sub-Saharan Africa may be due to a lack of diagnostic facilities which limit its study. ${ }^{33}$ Facilities for stress ECG, echocardiography, coronary angiography, myocardial scintigraphy, and measurements of cardiac enzymes are available only in a few urban health centers. There is a need to put in place appropriate diagnostic facilities in order to enable early diagnosis of $\mathrm{CAD}$ and its complications.

The absence of peripartum cardiac failure amongst our patients is interesting. A similar low prevalence has been noted 
in other parts of southern Nigeria. ${ }^{6}$ This contrasts sharply with reports from northern Nigeria where the incidence of peripartum cardiac failure, from peripartum cardiomyopathy, is probably the highest in the world. ${ }^{8,34}$ In addition to the presence of anemia in nearly $80 \%$ of cases, the postpartum customs and practices of taking hot baths and lying on heated beds to stay warm, as well as the ingestion of large amount of local salt to ensure adequate breast milk flow, have been mentioned as important factors in its pathogenesis. ${ }^{34}$ This practice has not been reported in the various populations of Nigerians in the Niger Delta basin of southern Nigeria.

This study was hindered by a number of limitations. Sample size was diminished by a lack of investigations such that diagnosis for some cases was clinical and could not be totally relied upon. This is because medical bills are shouldered by the patient or relatives and many patients cannot afford to pay. Because this is a retrospective study, the accuracy of data could be doubtful. Some data were incomplete. Hospital studies such as ours have selection bias. Facilities for coronary artery angiography or stress ECGs were not available. Therefore, objective confirmation of the clinical diagnosis of CCF is often lacking.

Despite these limitations, these results contribute to the bridging of the gap in the knowledge of CCF in developing countries and the various geopolitical zones of Nigeria. This paper will generate ideas for further research. It has also added to the weight of evidence in support of the growing importance of noncommunicable diseases in Nigerian populations who are often believed to suffer from mainly infectious diseases.

In conclusion, the burden of CCF that is mainly attributed to hypertension is quite high in our hospital. The community prevalence of heart failure in the Niger Delta may be higher than that reported from this hospital based study. Heart failure from ischemic heart disease is still rare as well as peripartum heart failure which is mainly found in Northern Nigeria.

\section{Acknowledgments}

The authors thank Professor Ndu Eke for his invaluable comments on the draft of this manuscript. We are also indebted to our colleagues who allowed us access to their patients' records for this study. The authors report no conflicts of interest in this work.

\section{References}

1. Mendez GF, Cowie MR. The epidemiological features of heart failure in developing countries: a review of the literature. Int J Cardiol. 2001;80:213-219.

2. Amoah AG, Kallen C. Aetiology of heart failure as seen from a National Cardiac Referral Centre in Africa. Cardiology. 2000;93:11-18.
3. Ladipo GO, Froude JR, Parry EH. Pattern of heart disease in adults of the Nigerian Savannah: a prospective clinical study. Afr J Med Med Sci. 1977;6:185-192.

4. Kingue S, Dzudie A, Menanga A, Akono M, Ouankou M, Muna W. [A new look at adult chronic heart failure in Africa in the age of the Doppler echocardiography: experience of the medicine department at Yaounde General Hospital]. Ann Cardiol Angeiol (Paris). 2005;54:276-283.

5. Stewart S, Wilkinson D, Becker A, et al. Mapping the emergence of heart disease in a black, urban population in Africa: the Heart of Soweto Study. Int J Cardiol. 2006;108:101-108.

6. Adewuya AO, Ola BA, Ajayi OE, Oyedeji AO, Balogun MO, Mosaku SK Prevalence and correlates of major depressive disorder in Nigerian outpatients with heart failure. Psychosomatics. 2006;47:479-485.

7. Abengowe CU. Cardiovascular disease in Northern Nigeria. Trop Geogr Med. 1979;31:553-560.

8. Antony KK. Pattern of cardiac failure in Northern Savanna Nigeria. Trop Geogr Med. 1980;32:118-125.

9. Dzudie A, Kengne AP, Mbahe S, Menange A, Kenfack M, Kingue S. Chronic heart failure, selected risk factors and co-morbidities among adults treated for hypertension in a cardiac referral hospital in Cameroon. Eur J Heart Failure. 2008;10:367-372.

10. Owusu IK. Causes of heart failure as seen in Kumasi, Ghana. The Internet Journal of Third World Medicine. 2007;5:1. Available from: http://www.ispub.com/ostia/index.php?xmlFilePath=journals/ijtwm/ vol5n1/ghana.xml. Accessed July 8, 2009.

11. Olubodun JO, Lawal SO. Alcohol consumption and heart failure in hypertensives. Int J Cardiol. 1996;53:81-85.

12. Karaye KM, Sani MU. Factors associated with poor prognosis among patients admitted with heart failure in a Nigerian tertiary medical center: a cross-sectional study. BMC Cardiovasc Disord. 2008;8:16.

13. Danbauchi SS, Alhassan MA, David SO, Wammanda R, Oyati IA. Spectrum of rheumatic heart disease in Zaria, Northern Nigeria. Ann Afr Med. 2004;3:17-21.

14. Ogah SO. Hypertension in Sub-Saharan populations: The burden of hypertension in Nigeria. Letter to the editor. Ethn Dis. 2006;16:765.

15. Adedoyin RA, Adesoye A. Incidence and pattern of cardiovascular disease in a Nigerian teaching hospital. Trop Doct. 2005;35:104-106.

16. Agomouh DI, Unachukwu CN. Pattern of non-communicable diseases among medical admissions in Port Harcourt, Nigeria. Niger Med Pract. 2007;51:45-50.

17. Ogunniyi A, Baiyewu O, Gureje O, et al. Morbidity pattern in a sample of elderly Nigerians resident in Idikan community, Ibadan. West Afr J Med. 20:227-231.

18. Jessup M, Brozena S. Heart failure. N Engl J Med. 2003;348: 2007-2018.

19. Smith SM, Mensah GA. Population aging and implications for epidemic cardiovascular disease in sub-Saharan Africa. Ethn Dis. 2003;13: s77-s80.

20. Onwuchekwa AC. Problems of hypertensive care in Nigeria. Niger Med Pract. 1996;31:94-96.

21. Toure IA, Salissou O, Chapko MK. Hospitalizations in Niger (West Africa) for complications from arterial hypertension. Am J Hypertens. 1992;5(5 Pt 1):322-324.

22. Obasohan AO, Ajuyah CO. How common is heart failure due to systemic hypertension in hospitalised Nigerians? J Hum Hypertens. 1996;10(12):801-804.

23. Falase AO, Ayeni O, Sekoni GA, Odia OJ. Heart failure in $\mathrm{N}$ igerian hyper tensives. Afr J Med Med Sci. 1983;12:7-15.

24. Kengne AP, Ozudie A, Sobngwi E. Heart failure in sub-Saharan Africa: a literature review with emphasis on individuals with diabetes. Vasc Health Risk Manag. 2008;4:123-130.

25. Kengne AP, Amoah AG, Mbanya JC. Cardiovascular complication of diabetes mellitus in sub-Saharan Africa. Circulation. 2005;112: 3592-3601.

26. Obasohan AO, Ajuyah CO. Heart failure in Nigerian hypertensive patients: the role of renal dysfunction. Int J Cardiol. 1995;52: 251-255. 
27. Busari OA, Opadijo OG, Adeyemi DA. Cardiac diseases in HIV and AIDS. The Internet Journal of Cardiology. 2008;5:2. Available from: http://www.ispub.com/journal/the_internet_journal_of_cardiology/ volume_5_number_2_6/article/cardiac_diseases_in_hiv_and_aids. html. Accessed July 10, 2009.

28. Twagirumukiza M, Nkeramihigo E, Seminega B, Gasakure E, Boccara F, Barbaro G. Prevalence of dilated cardiomyopathy in HIV infected African patients not receiving HAART: a multicentre, observational, prospective, cohort study in Rwanda. Curr HIV Res. 2007;5:129-137.

29. Connor MD, Lammie GA, Bell JE, Warlow CP, Simmonds P, Brettle RD. Cerebral infarction in adult AIDS patients: observation from the Edinburgh HIV autopsy cohort. Stroke. 2003;31:2117-2126.
30. Kingue S, Binam F, Pouth SF, Ouankou MD, Muna WF. Coronary artery disease in Cameroon: epidemiological and clinical aspects (30 cases). Ann Oncol. 2000;26:7-11.

31. Sanu MU, Mohammed AZ, Bapp A, Borodo MM. A three year review of mortality patterns in the medical wards of Aminu Kano Teaching Hospital, Kano, Nigeria. Niger Postgrad Med J. 2007;14:347-351.

32. Mensah GA. Global burden of cardiovascular disease. Ischaemic heart disease in Africa. Heart. 2008;94:836-843.

33. Kengne AP, Amoah AG, Mbanya J. Cardiovascular complications of diabetes mellitus in sub-Saharan Africa. Circulation. 2005;112: 3592-3601.

34. Danbauchi SS. Echocardiographic features of peripartum cardiac failure: the Zaria syndrome. Trop Doct. 2002;32:24-27.

\section{Publish your work in this journal}

Vascular Health and Risk Management is an international, peerreviewed journal of therapeutics and risk management, focusing on concise rapid reporting of clinical studies on the processes involved in the maintenance of vascular health; the monitoring, prevention and treatment of vascular disease and its sequelae; and the involvement of metabolic disorders, particularly diabetes. This journal is indexed on PubMed Central and MedLine. The manuscript management system is completely online and includes a very quick and fair peer-review system, which is all easy to use. Visit http://www.dovepress.com/ testimonials.php to read real quotes from published authors. 